\title{
Epidemic of Mycoplasma pneumoniae infection in Denmark, 2010 and 2011
}

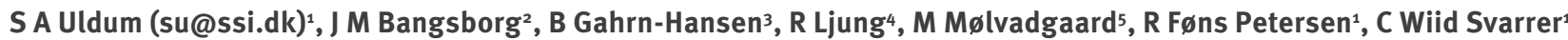

1. Statens Serum Institut, Copenhagen, Denmark

2. Department of Clinical Microbiology, Herlev University Hospital, Herlev, Denmark

3. Department of Clinical Microbiology, Odense University Hospital, Odense, Denmark

4. Department of Clinical Microbiology, Nordsjællands Hospital, Hillerød, Denmark

5. Department of Clinical Microbiology, Aalborg Sygehus Syd, Aalborg, Denmark

Citation style for this article:

Uldum SA, Bangsborg JM, Gahrn-Hansen B, Ljung R, Mølvadgaard M, Føns Petersen R, Wiid Svarrer C. Epidemic of Mycoplasma pneumoniae infection in Denmark, 2010 and 2011.

Euro Surveill. 2012;17(5):pii=20073. Available online: http://www.eurosurveillance.org/ViewArticle.aspx?Articleld=20073

Article published on 2 February 2012

Denmark experienced two waves of Mycoplasma pneumoniae infection during autumn and early winter in 2010 and 2011, respectively. Both affected the whole country. The proportion of positive results was almost the same for both, indicating that the two waves were probably of equal size. High macrolide consumption during the epidemics did not seem to affect levels of macrolide resistance in $M$. pneumoniae, which remain low in Demark (1\% to $3 \%$ ).

Epidemics of Mycoplasma pneumoniae infection are normally seen at intervals of four to seven years $[1,2]$. In some cases, simultaneous epidemics are seen in more than one country. In 2010, Denmark [1], England and Wales [2], Sweden [3] and Finland [4] reported more cases of $M$. pneumoniae infection than normal. In autumn 2011, reports from Norway [5], Sweden [3], the Netherlands [6] and Finland [4] indicated an epidemic of $M$. pneumoniae infection in the northern part of Europe. In Denmark, we have also seen a rise in the number of M. pneumoniae cases during autumn 2011.

The surveillance of $M$. pneumoniae in Denmark has been described previously [1].The system is based on laboratory data from Statens Serum Institut (SSI). SSI receives samples (almost an equal number of blood/ serum samples for serology and respiratory samples for P(R) from hospitals and general practitioners for routine diagnosis. The diagnosis and surveillance of M. pneumoniae infection used to be based on serology in the past, but since the beginning of the 1990s, PCR has been introduced as a routine test at SSI for rapid and early diagnosis of $M$. pneumoniae. A rise in the rate of PCR positive samples at SSI from $<5 \%$ to $15 \%$ or more is considered as indicative of an epidemic [1]. During the last decade, the diagnosis of $M$. pneumoniae has been moved from SSI to local hospital laboratories which have also progressively introduced PCR as a routine diagnostic test for $M$. pneumoniae over the past years. In the beginning of October 2010, SSI saw an increase in the proportion of positive samples above the threshold (>15\%) [7] (Figure 1). This tendency was confirmed by data from hospital laboratories in Denmark and in November 2010 Denmark reported a nation-wide increase in the number and proportion of M. pneumoniae PCR positive samples [1]. According to SSI laboratory data, the epidemic peaked in midDecember 2010, while the number decreased rapidly during the rest of December and in January 2011. The number of cases seemed to return to a normal level during spring and early summer 2011 (Figure 1). An increase was observed again in late summer and early autumn 2011 [8]. This prompted SSI to contact a selection of local laboratories all over the country, with a request to submit laboratory data on a weekly basis for M. pneumoniae PCR for 2011, to monitor if the rise could be confirmed and if it was nation-wide. The laboratories were selected to cover and represent most of the country, the eastern part (The Capital and Zeeland) the mid-south (Funen) and the north-western part (Northern Jutland).

Macrolide resistance in $M$. pneumoniae is a growing problem especially in East Asia, but it is also seen in the United States and Europe [9]. During an epidemic of M. pneumoniae, the macrolide consumption is known to increase considerably $[10,11]$. In December 2010, Denmark saw the highest consumption in a single month (3.9 defined daily doses (DDD)/1,00o population) compared to the consumption in December during the previous nine years $(2.5 \mathrm{DDD} / 1,000$ population on average). According to provisional data, the consumption in November 2011 was the highest for the month of November (3.6 DDD/1,000 population) compared to the last 10 years (2.4 DDD/1,000 population on average for November months between 2001 and 2010) personal communication, Maja Laursen, the Danish Medicines Agency, January 2012. 


\section{Laboratory investigation}

SSI is situated in the Capital Region of Denmark and receives samples predominantly from the Capital Region and the Region Zealand. To further investigate if the rise in the absolute number and in the proportion of positive tests was seen all over the country, the institute received and analysed weekly data from four hospital laboratories (North Denmark Region, Region of Southern Denmark and two laboratories from the (apital Region).

To compare the years 2009 (no epidemic) with the two epidemic years (2010 and 2011) SSI requested in January 2012 results for the period from 2009 to 2011. Data for the whole period were provided by two hospital laboratories (North and Capital 1) and by SSI. The South Denmark region laboratory provided data for 20 September 2010 (week 38) to 31 December 2011 (week 52) and Capital 2 laboratory provided data for 29 August 2011 (week 35) to 31 December 2011 (week 52). Capital 2 also provided data for the epidemic period in 2010 but only for eight weeks (25 October to 19 December 2010) and not on a weekly base but in an aggregated form (Table).The number of positive samples per week from each laboratory is presented in Figure 2. Both waves of the $M$. pneumonia epidemic were seen in the whole country almost simultaneously (Figure 2).
To compare the two epidemic periods, data for the same period (week 43 to week 50) for the two years from the five laboratories are presented in the table. The peak periods for both epidemic waves were within the selected eight weeks. Twice the number of positive samples (1.9 times) were detected in 2011 compared with 2010 , but the number of samples investigated were also almost twice (1.8 times) as high in 2011 compared with 2010. The proportion of positive samples was in general equal during both waves (in average $15 \%-16.3 \%$ ) but for North Denmark Region, the rate was higher in $2011(17.3 \%)$ compared with 2010 (14.5\%) despite the fact that more than a double number ( 2.6 times) of samples were tested (Table).

In 2010, the five laboratories diagnosed approximately $70 \%$ of all cases in Denmark; assuming that this also applies for 2011, it can be estimated that more than 4,600 cases were diagnosed in Denmark (the country's population counts 5.5 million inhabitants) during the eight-week period from 24 October to 18 December 2011. This corresponds to an incidence of approximately 10 new PCR diagnosed cases per 100,000 population per week in Denmark. In the North Denmark Region, one laboratory received all samples from the region for M. pneumoniae PCR. The population size of the region is 580,000 and 125 samples on average were positive per week (Table) giving an estimated incidence of more than 20 new cases per 100,000 population per week. In

\section{FIGURE 1}

Positive Mycoplasma pneumoniae PCR samples at Statens Serum Institut, Denmark, 1 January (week 1) 2009 to 29 January (week 4) 2012

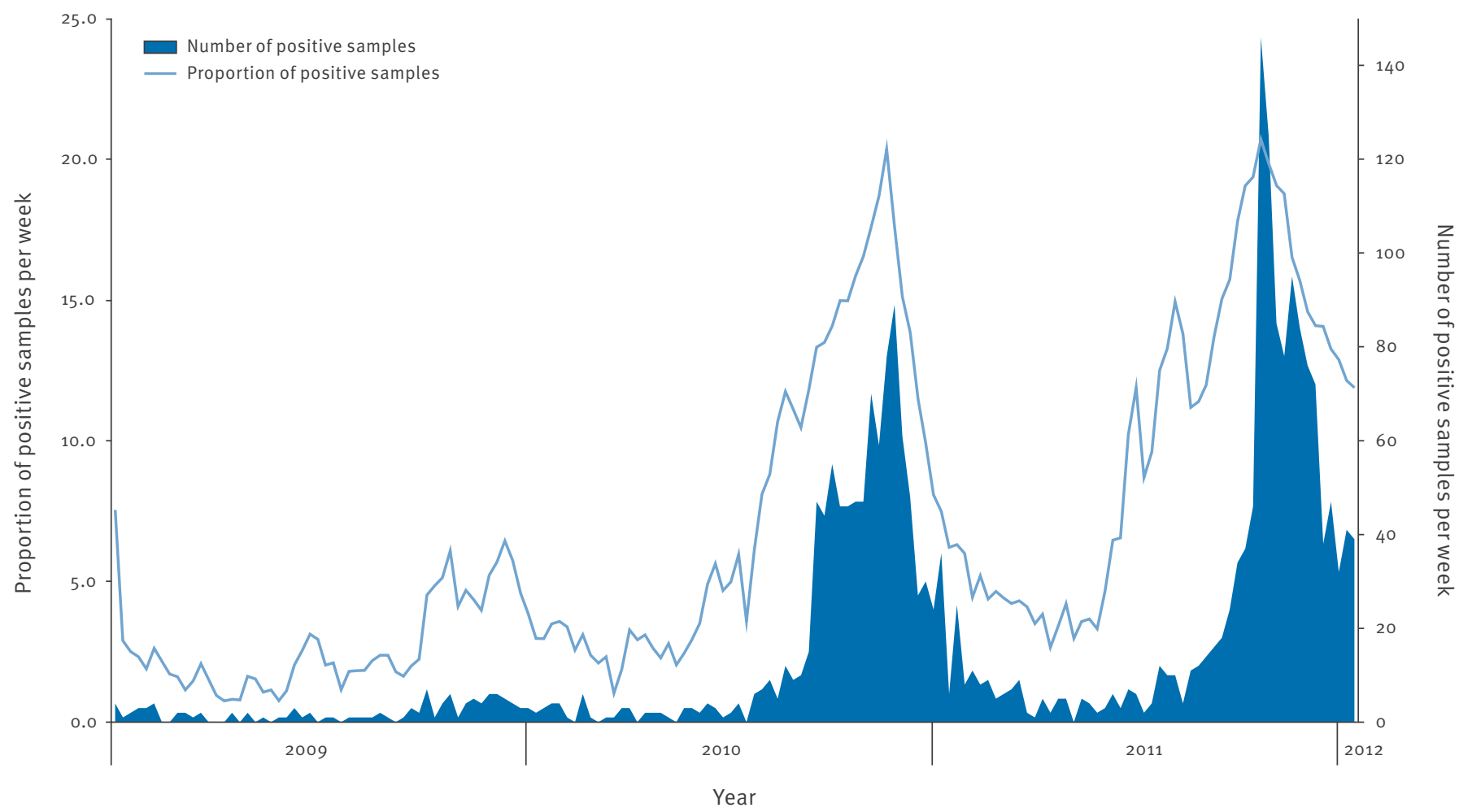

The proportion of positive tests is the floating average of four weeks. 
2010, the estimated incidence for this region was only eight per 100,000 population per week. The diagnostic activity for this region was almost 1 per 100 population during the eight-week period. The diagnostic activity for the whole country can be estimated from the figures in the table. If we consider the five laboratories representing $70 \%$ of the diagnostic activity, approximately five persons per 1,000 population were investigated during the eight weeks.

At SSI, we also investigated the prevalence of macrolide resistance for both 2010 and 2011. Macrolide resistance-associated mutations in the gene for the 23 SRNA were identified with a sequencing technique developed at SSI. The technique can be performed directly on DNA purified from PCR positive samples [12]. We did a survey on 140 PCR positive samples consecutively received at SSI during late September and early October 2010 (the beginning of the first wave) and on 108 PCR positive samples consecutively received in January 2011 (the end of the first wave). During the second wave in 2011 we investigated 117 PCR positive samples received in late October and in the beginning of November, representing the beginning of the 2011 wave. In the first wave we found two (1.4\%) and three $(2.9 \%)$ mutations, respectively, and in the second wave we only found one sample with a mutation (0.9\%). Data for PCR positive samples from January 2012 (the end of the second wave) are currently unavailable.

\section{Discussion and conclusions}

In two successive years, Denmark experienced a high number of M. pneumonia infections during autumn and early winter. The situation can be characterised as one epidemic consisting of two waves. Epidemics spanning two autumn/winter seasons were also seen in Denmark in 1962 to 1964 , in 1971 to 1973 and to some degree also in 2004 to 2006 [1]. The total number of PCR positive samples in 2011 was twice the number in 2010, but the number of investigated samples was also twice as high in 2011 compared with 2010 (Table). We are unable to determine whether this reflects a true increase in the number of cases from the 2010 wave to the 2011 wave or whether this reflects an increase in the awareness of the public and among physicians. However, as the proportion of positive samples was almost equal during the two periods, it is reasonable to assume that the two waves were of almost equal size, but the duration of the 2011/12 wave seems to be longer with a more gradual decline than the 2010 wave (Figure 1). However, it seems obvious that the 2011 wave was more extensive than the 2010 wave in the North Denmark Region, and it seems also likely that this region was more affected by the second wave than

\section{FIGURE 2}

Number of PCR positive samples from five selected laboratories in Denmark, 2009 to 2011

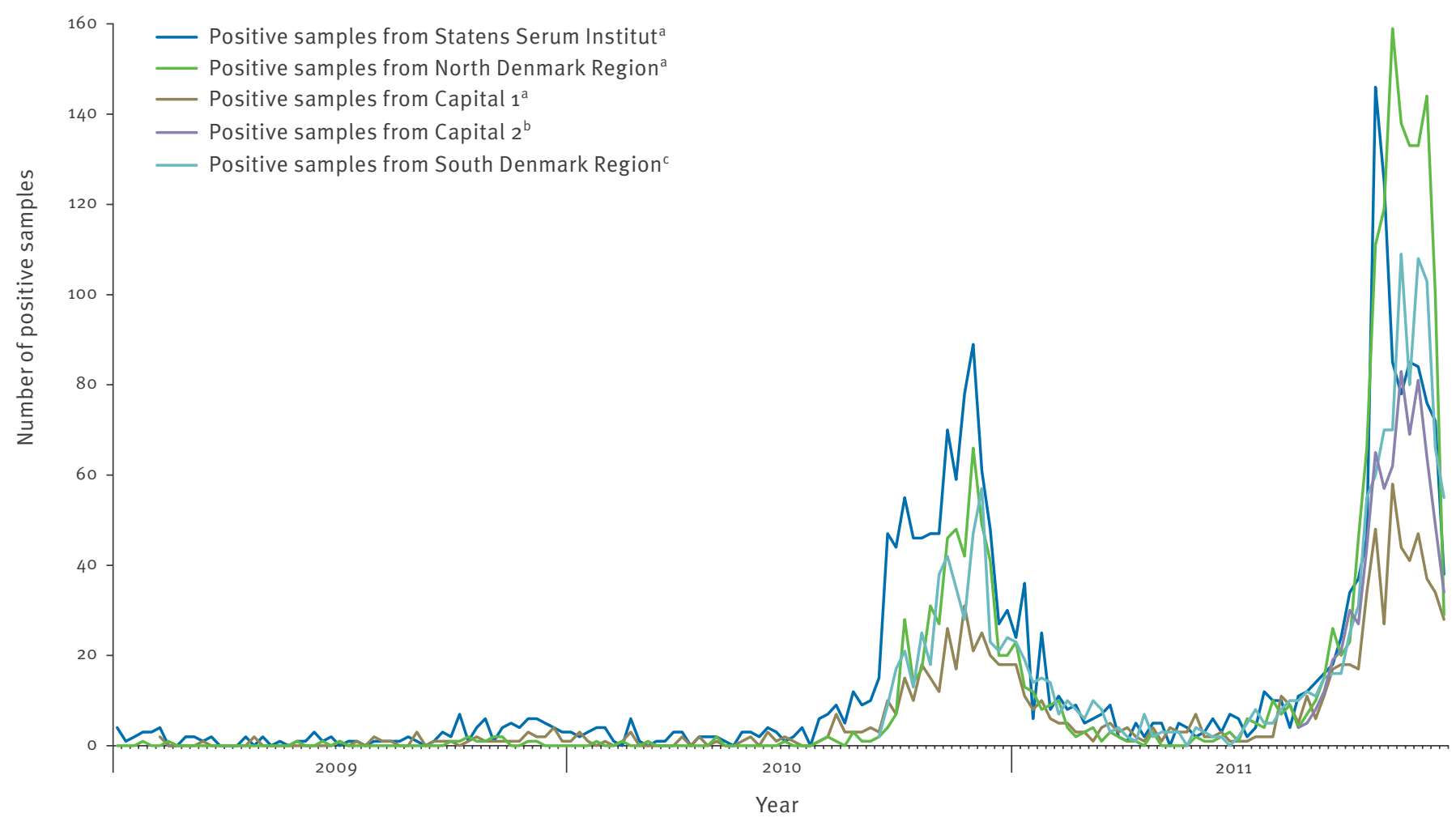

\footnotetext{
Data were provided for the whole period (2009-2011).

b Data were provided for 25 October - 19 December 2010 and for 29 August - 31 December 2011.

Data were provided for 20 September 2010 - 31 December 2011.
} 
the rest of the country. Although there are differences between the regions, both waves hit the whole country almost simultaneously (Table and Figure 2). The incidence and diagnostic activity for the other regions cannot be estimated as we do not know the population base for the other laboratories. The diagnostic activity for the whole country ( 5 per 1,000 population) can only be estimated under the assumption that the five laboratories represent $70 \%$ of the diagnostic activity during the epidemic. However, a diagnostic activity of approximately 1 per 100 population in North Denmark Region during the eight-week period in 2011 can be considered as high.

The estimated average incidence of PCR diagnosed cases during the epidemic in 2011 was approximately 10 new cases per 100,000 population per week; this is probably a vast underestimation of the real number of cases of $M$. pneumoniae infection during this period, as many patients with mild symptoms will not consult their general practitioner, and only a fraction of patients who visit a practitioner will have samples collected for M. pneumonia PCR.

Although the consumption of macrolides is high during an epidemic of $M$. pneumonia it does not seem to influence the prevalence of macrolide resistance in M. pneumoniae. This is in contrast to other respiratory pathogens, such as Streptococcus pneumoniae, where resistance is closely linked to increased macrolide use [13]. This link was also observed following a previous Danish M. pneumoniae epidemic in 1998/99 [11]. However, we still need to investigate samples collected in January 2011 before any categorical statement on M. pneumoniae susceptibility to macrolides. Macrolide resistance in $M$. pneumoniae may be characterised as low in Denmark, as there is still no general problem, but in specific cases, macrolide resistance can lead to relapse and prolonged disease [12].

\section{TABLE}

Number and proportion of Mycoplasma pneumoniae samples tested by PCR at five laboratories, Denmark, 25 October (week 43) to 19 December (week 50) 2010 and 24 October (week 43) to 18 December (week 50) 2011

\begin{tabular}{|c|c|c|c|c|}
\hline \multirow[b]{2}{*}{$\begin{array}{l}\text { Laboratory } \\
\text { (region) }\end{array}$} & \multicolumn{2}{|c|}{ Weeks 43-50 2010} & \multicolumn{2}{|c|}{ Weeks 43-50 2011} \\
\hline & $\begin{array}{c}\text { Number of } \\
\text { samples }\end{array}$ & $\begin{array}{c}\text { Number of } \\
\text { positive } \\
\text { samples (\%) }\end{array}$ & $\begin{array}{c}\text { Number of } \\
\text { samples }\end{array}$ & $\begin{array}{c}\text { Number of } \\
\text { positive } \\
\text { samples (\%) }\end{array}$ \\
\hline $\mathrm{SSI}^{\mathrm{a}}$ & 3,091 & $497(16.1)$ & 4,393 & $725(16.5)$ \\
\hline Capital 1 & 1,109 & $165(14.9)$ & 2,412 & 336 (13.9) \\
\hline Capital 2 & 2,669 & $349(13.1)$ & 3,300 & $519(15.7)$ \\
\hline North & 2,253 & $362(14 \cdot 5)$ & 5,787 & $1,003(17.3)$ \\
\hline Southern & 1,946 & $290(14.9)$ & 3,994 & $655(16.4)$ \\
\hline Total & 11,068 & $1,663(15.0)$ & 19,886 & $3,238(16.3)$ \\
\hline
\end{tabular}

a SSI: Statens Serum Institut.
We believe that it is important to have a national surveillance system for monitoring both the prevalence of the disease and the macrolide resistance in M. pneumoniae.

\section{Acknowledgments}

The authors thank Birthe Dohn at Statens Serum Institut for performing the DNA sequencing for macrolide resistance.

\section{References}

1. Rasmussen JN, Voldstedlund M, Andersen RL, EllermannEriksen S, Jensen TG, Johansen HK, et al. Increased incidence of Mycoplasma pneumoniae infections detected by laboratory-based surveillance in Denmark in 2010. Euro Surveill. 2010;15(45):pii=19708. Available from: http://www. eurosurveillance.org/ViewArticle.aspx?Articleld=19708

2. Chalker VJ, Stocki T, Mentasti M, Fleming D, Harrison TG. Increased incidence of Mycoplasma pneumoniae infection in England and Wales in 2010: multiocus variable number tandem repeat analysis typing and macrolide susceptibility. Euro Surveill. 2011;16(19):pii=19865. Available from: http://www. eurosurveillance.org/ViewArticle.aspx?Articleld=19865

3. Linde A. Mycoplasma aktuellt - igen. [Mycoplasma relevant - again]. Stockholm: Smittskyddsinstituttet. 3 Nov 2011. Swedish. Available from: http://www.smittskyddsinstitutet.se/ nyhetsarkiv/2011/mycoplasma-aktuellt--igen/

4. National Institute for Health and Welfare (THL). Mykoplasmaa edelleen liikkeellä. [Mycoplasma still circulating]. Helsinki: THL. 5 Dec 2011. Finnish. Available from: http://www.thl.fi/ en_US/web/en/

5. Folkehelseinstituttet. Økt forekomst av Mycoplasma pneumoniae infektioner. [Increased prevalence of Mycoplasma pneumoniae infections]. Oslo: Folkehelseinstituttet. Norwegian. Available from: http://www.fhi.no/eway/default.as px?Area_5774=5544:92470::1:5776:1:::0:0\&MainArea_5661=55 88:0:15,1787:1:0:0:::0:0\&MainLeft_5588=5774:0:15,1787:1:0:0 :::0:0\&pid=233\&trg=Area_5774

6. Rijksinstituut voor Volksgezondheid en Milieu (RIVM). Meldingen uit de virologische laboratoria tot en met week 44 2011. [Reports from the virological laboratories to week 44, 2011]. Bilthoven: RIVM. Dutch. Available from: http:// www.rivm.nl/Bibliotheek/Algemeen_Actueel/Uitgaven/ Infectieziekten Bulletin/Jaargang 22/December 2011/ Inhoud_december_2011/Meldingen_uit_de_virologische laboratoria_tot_en_met_week_44_2011

7. Statens Serum Institut (SSI). Mycoplasma pneumoniae: Increase. Copenhagen: SSI. EPI-NEWS. 2010;40. 6 Oct 2010. Available from: http://www.ssi.dk/English/News/EPINEWS $/ 2010 /$ No\% 2040\%20-\%202010.aspx

8. Statens Serum Institut (SSI). Increased number of Mycoplasma pneumoniae cases. Copenhagen: SSI. EPI-NEWS. 2011;41. 12 Oct 2011. Available from: http://www.ssi.dk/English/News/EPINEWS/2011/No\%2041\%20-\%202011.aspx

9. Dumke R, von Baum H, Lück PC, Jacobs E. Occurrence of macrolide-resistant Mycoplasma pneumoniae strains in Germany. Clin Microbiol Infect. 2010;16(6):613-6.

10. Statens Serum Institut, Danish Veterinary and Food Administration, Danish Medicines Agency, Danish Institute for Food and Veterinary Research. DANMAP 2005. Use of antimicrobial agents and occurrence of antimicrobial resistance in bacteria from food animals, food and humans in Denmark. Søborg: Statens Serum Institut, Danish Veterinary and Food Administration, Danish Medicines Agency, Danish Institute for Food and Veterinary Research. Jul 2006. Available from: http://www.danmap.org/Downloads/Reports.aspx

11. Statens Serum Institut (SSI). Increased resistance to macrolide antibiotics. Copenhagen: SSI. Epi-News; 2001;4. Available from: http://www.ssi.dk/English/News/EPI-NEWS/ /media/ Indhold/EN\%20-\%20engelsk/EPI-NEWS/2001/pdf/EPINEWS\%20-\%202001\%20-\%20No\%204.ashx

12. Uldum SA, Amberg P, Jensen JS. Macrolide resistance in Mycoplasma pneumoniae by recurrence and extenden illness. Ugeskr Laeger. 2011 Aug 1. Danish. [Epub ahead of print].

13. Bergman M, Huikko S, Huovinen P, Paakkari P, Seppälä $\mathrm{H}$; Finnish Study Group for Antimicrobial Resistance (FiRe Network). Macrolide and azithromycin use are linked to increased macrolide resistance in Streptococcus pneumoniae. Antimicrob Agents Chemother. 2006;50(11):3646-50. 